\title{
CORPOS SINGULARES: AUTOBIOGRAFIA, DECOLONIALIDADE E EDUCAÇÃO SOMÁTICA NO ENSINO DA DANÇA
}

\author{
Neila Cristina Baldi ${ }^{\mathrm{i}}$ \\ Oneide Alessandro Silva dos Santos ${ }^{\text {ii }}$ \\ Fabiana Andréia Mors ${ }^{\text {iii }}$ \\ Cinara Neujahr dos Santos ${ }^{\mathrm{iv}}$
}

\begin{abstract}
Resumo: No texto, é apresentada a investigação do Grupo de Pesquisa (Es)(Ins)critas do/no Corpo (Corpografias) do Curso de Dança-Licenciatura da Universidade Federal de Santa Maria. De março de 2018 a dezembro de 2020, o projeto desenvolve procedimentos para a Dança com a utilização da Autobiografia, Decolonialidade e Educação Somática. Para isso, na metodologia, foram utilizados: leituras de artigos, mapas conceituais com o levantamento de palavras disparadoras para criar os procedimentos que são testados no grupo de pesquisa e em projetos sociais e escolas. Concluiu-se que as práticas promovem discussões sobre pertencimento, interpretação, significação e democracia corporal, permitindo a construção de um sujeito autônomo e crítico, confrontando colonialidades constituídas, o pensamento e o ensino de Arte.
\end{abstract}

Palavras-chave: Ensino de Dança; Decolonialidade; Educação Somática; Autobiografia; Metodologia.

\section{CUERPOS SINGULARES, AUTOBIOGRAFÍA, DECOLONIALIDAD Y EDUCACIÓN SOMÁTICA EN ENSEÑANZA DE LA DANZA}

Resumen: El texto presenta la investigación del Grupo de Pesquisa (Es)(Ins)critas do/no Corpo (Corpografias) del Curso de Profesorado en Danza de la Universidade Federal de Santa Maria. Desde marzo de 2018 hasta deciembre de 2020, el proyecto desarrolla procedimientos para la Danza basados en Autobiografía, Decolonialidad y Educación Somática. Para esto, la metodología utilizada fue: lecturas de artículos, mapas conceptuales con el levantamiento de palabras de activación para crear los procedimientos que se prueban en el grupo de investigación y en proyectos sociales y escuelas. Concluye que las prácticas promueven discusiones sobre pertenencia, interpretación, significación y democracia corporal, permitiendo la construcción de un sujeto autónomo y crítico, confrontando las colonias constituidas, el pensamiento y la enseñanza del Arte.

Palabras-claves: Enseñanza de la Danza; Decolonialidad; Educación Somática; Autobiografía; Metodología. 


\section{Introdução}

A ampliação do número de cursos de graduação em Dança no Brasil tem permitido a emergência de novas pesquisas sobre dança, inclusive aquelas que dizem respeito às metodologias de ensino. Até os anos 1980, o país contava com apenas três cursos superiores de Dança. Com o Programa de Apoio a Planos de Reestruturação e Expansão das Universidades Federais (Reuni), em 2008, foram criados outros 16 cursos em instituições federais, além daqueles que surgiram tanto em entidades públicas quanto privadas, que culminaram com 41 em 2016. O que significa que, hoje, a graduação em Dança no Brasil implica o desenvolvimento desta na educação básica (VIEIRA, 2019, p. 124), muito embora não garanta a efetiva inserção dos(as) profissionais no mercado do trabalho. O que queremos dizer com isso é que a ampliação das graduações em Dança no país permite que a dança, de fato, vá para a escola - teoricamente é possível oficialmente desde a Lei de Diretrizes e Bases da Educação, de 1996 - e, estando neste ambiente, é impossível se imaginar que a mesma aula praticada em escolas de dança seja realizada no ensino formal.

Desse modo, consideramos que a ida da dança para a escola e a ampliação da dança no meio acadêmico têm permitido a revisão das perspectivas epistemológicas, pedagógicas e metodológicas. Ademais, se antes o(a) bailarino(a) virava professor(a), agora, passa por uma formação artístico e pedagógica que lhe oferece a oportunidade de repensar sua prática, o que significa que não faz mais sentido reproduzir as aulas dos(as) mestres(as).

Além disso, houve um movimento na dança cênica de mudança de pensamento sobre dança e sobre corpo que, no mundo acadêmico, também está em voga. O corpo, anteriormente, era pensado como instrumento. O ensino da dança, nesse sentido, era treinamento, como uma atividade mecânica, no qual os(as) estudantes deveriam [...]aprender determinados movimentos, ou seja, passos característicos da dança ocidental e adquirir habilidades como girar, equilibrar e dominar a articulação do pé. (WOODRUFF, 1999, p. 33) Dessa forma, a aula se dava pela repetição de movimentos. Em uma aula de dança e, portanto, Arte, reproduzia-se o modelo da escola formal, ou seja, do controle do corpo, alheio às manifestações sensíveis.

A partir da modernidade, há um percurso, na dança cênica ocidental, [...] do corpo para si, ainda que, mediado primeiramente por uma aproximação do corpo à realidade social, política e artística de então (RIBEIRO, 1997, p. 9). E, nos anos 1960, começou uma dissolução de fronteiras entre dança, teatro, performance e música vocal, quando [...] artistas 


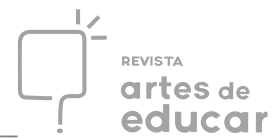

se concentram sobre o corpo, o seu e o do público, e o tomam como objeto privilegiado de trabalho e de reflexão: o corpo expressa o corpo. (RIBEIRO, 1997, p. 20), ou seja, há uma mudança em relação ao pensamento sobre o corpo.

Pensamento outro (WALSH, 2008) sobre o corpo significa também pensamento outro sobre dança e, consequentemente, sobre o que seja o treinamento em dança, de onde se depreende que outras formas de aprender e ensinar dança passam a coexistir - assim como os pensamentos a respeito de corpo, que já não são únicos. Com a dança contemporânea, todos os corpos podem dançar - magros, gordos, com ou sem deficiência etc. - e o corpo, então, não é mais visto como instrumento: eu sou corpo.

Acreditando que existem modos outros de dançar e, portanto, de ensinar e aprender dança, o Grupo de Pesquisa sobre (Es)(Ins)critas do/no Corpo (Corpografias), da Universidade Federal tem se dedicado a investigar procedimentos de ensino e criação em dança. A pesquisa, em andamento, que será discutida neste texto, iniciou-se em março de 2018, com previsão de término no final do ano que vem. Até o momento, dez procedimentos foram testados e outros dez produzidos. As discussões empreendidas até o momento partem de três campos epistemológicos: Autobiografia, Decolonialidade e Educação Somática. Em comum, ambos compreendem o corpo pela sua singularidade e suas marcas. Os dois primeiros percebem o corpo como corpo-sujeito histórico e social, enquanto o último não separa corpo de mente e compreende que o 'corpomente' está imbricado por suas relações físicas, psíquicas, sociais etc.

O grupo tem operado com a seguinte metodologia: leitura, debate e fichamento de textos sobre as temáticas da Decolonialidade, da Educação Somática e da Autobiografia. Fazse um levantamento, com discussões, de palavras-chave disparadoras para a produção de procedimentos de ensino e construção individual destes. Posteriormente, teste dos procedimentos, dentro do grupo, com debate sobre possíveis variações, objetivos, conteúdos e faixas-etárias para as quais os procedimentos foram criados. Em uma penúltima etapa, experimentação dos procedimentos em ONGs e escolas do ensino formal, com diferentes públicos. Por fim, debate dos resultados e construção coletiva de uma ficha dos procedimentos que virá a constituir uma publicação específica, destinada a docentes. Até o momento, 10 procedimentos foram construídos e testados - entre eles, Fragmentos de um Corpo Decolonial, Caixa Preta, Entre Nós, Formas Diferentes de Dançar, PalaDança e Texturas para Dançar, citados a seguir - e outros 10 estão em fase de testes. 


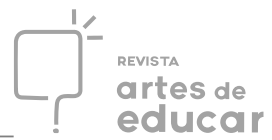

Este texto apresenta a investigação, em andamento, sobre procedimentos metodológicos para ensino e criação em Dança com estudos da Decolonialidade, Educação Somática e Autobiografia, tendo como ênfase os estudos e produções deste ano. Para isso, discutiremos cada um dos campos epistemológicos referenciais para a pesquisa e, posteriormente, refletiremos sobre o conceito de corpo presentes nestes campos, assim como possíveis entendimentos pedagógicos advindos deste conceito e de outras conceituações importantes para os três campos. Por fim, apresentaremos as conclusões provisórias oriundas das discussões ao longo do ano de 2019.

\section{Autobiografia e o (re)conhecimento de si}

O campo da Autobiografia se constituiu na metade do século passado e compreende diversas formas de pesquisa, a depender dos métodos empregados, desde histórias de vida, narrativas de si, autobiografias, biografias educativas, entre outros termos, abrangendo pesquisas que analisam como [...] os indivíduos vivem e representam a sua existência [...] (FORTUNA, 2012, p. 167). No campo da Educação, a Autobiografia tem sido usada como metodologia de pesquisa - como dado - e metodologia pedagógica de formação - porque escrever sobre si é conhecer-se e, portanto, é autoformador.

$\mathrm{Na}$ Dança, a Autobiografia surge também na segunda metade do século XX, quando interessa aos criadores e criadoras trazer à tona temas pessoais. Ou seja, falar de si, de suas histórias, de suas vivências passa a ser temática das obras de dança, bem como questões a serem observadas em processos de criação. A utilização de dados autobiográficos em composições cênicas emerge na cena moderna e contemporânea como uma possibilidade do sujeito ser criador de sua própria arte (PERES, 2014, p. 81). A autora cita Pina Bausch como uma das expoentes no uso da Autobiografia em cena, com o método das perguntas e respostas, em que o(a) bailarino(a) respondia perguntas ou propostas que fundamentam [... $o$ processo criativo na história e na verdade do intérprete, estimulando-o à criação através de uma relação parceira (GREBLER, 2008, p. 103).

Se por um lado a Dança usa a autobiografia para a criação e a Educação, para a pesquisa e como método para a formação de professores(as), como seria, então, pensar a Autobiografia para a dança na escola ou para o ensino da dança? O Grupo Corpografias vem desenvolvendo procedimentos de ensino de dança - que podem se configurar, também, como 


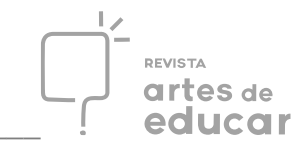

de criação - para as mais diferentes idades, sem necessariamente propor que a Autobiografia seja considerada, como na Educação, um processo formativo, ou seja, para [...] conhecer $e$ compreender os significados que cada um atribui ou atribuiu em cada período da sua existência aos acontecimentos e situações que viveu (JOSSO, 2010, p. 68). A ideia, aqui, é que a temática da vida dos(as) estudantes possa ser currículo, possa promover o desenvolvimento de determinados conteúdos de dança. Assim, neste ano de 2019, com os estudos de Josso (2010), Chiené (2010), Passegi, Abrahão e Delory-Momberger (2012) e Foucault (1992) foram desenvolvidos procedimentos, sendo dois destes aqui discutidos: Caixa Preta e Entre Nós. Ambos podem servir para trabalhar tanto improvisação quanto criação em dança, com adolescentes. Segundo Josso (2010, p. 66):

A imagem da 'caixa negra' serve aqui para ilustrar a ideia de que os processos cuja compreensão se pretende atingir podem ser clarificados por um trabalho introspectivo, por uma atenção particular, que as pedagogias das nossas instituições educativas deixam, a maior parte das vezes, na penumbra. Essa 'atenção interior', consciência proprioceptiva, é a única competência de que dispúnhamos para investigar a "caixa negra" [...] A maioria dos nossos estudantes pratica essa Atenção Interior para se consciencializar dos movimentos das suas emoções e sentimentos [...]

Imaginar que temos nossas caixas pretas, aquele espaço em que estão guardados sentimentos, sensações, imagens que, por vezes, são difíceis de acessar, motivou a criação do procedimento, no qual são colocadas palavras-chave para cada etapa de vida do(a) estudante. Isto porque, de acordo com Chiené (2012, p. 12), [...] por meio da escrita, o indivíduo dá, de certa forma, uma substância ao seu ser, no termo da sua formação. Compreendemos, então, os movimentos dançados como a escrita dos(as) nossos(as) alunos(as) a respeito das suas autobiografias.

A autora(idem) lembra, ainda, que a formação se dá na articulação do espaço pessoal com o social. Aqui, na proposição criada, a ideia é que os(as) estudantes coloquem papeis com suas palavras-chave na caixa preta e, depois, o grupo sorteie aquelas que serão usadas para desenvolver movimentos dançados, o que significa que a história pessoal passará a ser coletiva. Ninguém dançará especificamente a sua história, mas um conjunto de imagens da caixa preta coletiva. Isto nos permite inferir que o pessoal também é social, uma vez que Delory-Momberger (2012, p. 75) afirma: [...] as histórias que contamos sobre nós mesmos e que, 


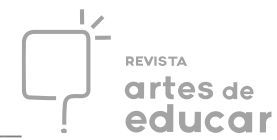

segundo alguns, nós dirigimos a outros, longe de nos jogar numa intimidade inacessível, têm por efeito articular nosso espaço-tempo individual ao espaço-tempo social.

Nesse sentido, estamos produzindo danças singulares e plurais. Singulares porque partem de cada pessoa, de seus pensamentos e memórias, e plurais, porque os temas são universais.

Uma questão que emerge deste procedimento é: o que está em nossa caixa preta? O que mostramos e o que escondemos? Oliveira (2011) afirma que tanto a memória quanto o esquecimento nos trazem à tona os processos significativos e as aprendizagens ocorridas. Podemos refletir não apenas sobre as lembranças/esquecimentos das palavras-chave, mas também sobre, na produção do movimento dançado, o que escolhemos mostrar, o que produzimos e o que escondemos quando estamos dançando. Do ponto de vista de composição coreográfica, por exemplo, um questionamento que pode surgir é o do movimento sombra daquele mostrado: qual seria o movimento escondido deste reproduzido? O que seria a sombra - no sentido de não mostrado - deste ou daquele movimento dançado?

O outro procedimento criado parte do pensamento de Josso (2004) sobre os momentos-charneira. Essa autora (2010, p. 70) afirma que são nesses momentos que [...] $o$ sujeito confronta-se consigo mesmo. Seguindo esse entendimento, criamos o procedimento 'Entre Nós', que propunha que cada aluno(a) fizesse em um barbante tantos nós quanto momentos-charneira de sua vida, de modo que cada nó teria a sua particularidade: ser menor, maior, mais apertado, mais frouxo, ou seja, a proposta era a de o(a) estudante faria no seu barbante diversos nós, de tamanhos variados, conforme a importância de cada momento lembrado. Posteriormente, o(a) aluno(a) deveria, de olhos fechados, passar a mão no seu barbante, de modo a sentir as variações porque passou ao longo da sua vida, em um entendimento de que aquela narrativa no fio, [...] apresenta-se como uma sucessão de estados, na qual cada estudante pode [...] referenciar os desvios, as diferenças que aparecem como uma sucessão na narrativa [...] (CHIENÉ, 2010, p. 134). Com a percepção dessas variações, o(a) estudante estrutura movimentos dançados para o seu fio de barbante. Assim como o procedimento anterior, os conteúdos de dança aqui trabalhos também eram a improvisação e a criação. Nesse procedimento, propusemos uma variação: trocar os fios, ou seja, um(a) aluno(a) dançaria o fio de outro(a), sem saber de quem e cada um apresentaria sua construção de modo que o criador do fio e a pessoa que o recebeu pudessem mostrar ao mesmo tempo para que a plateia percebesse variações e semelhanças - do ponto de vista de dinâmica - nos movimentos de ambos(as). Outra opção também seria juntar fios, amarrando- 


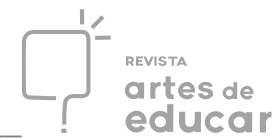

os e criar dança para vários fios unidos, sem necessariamente saber a quem pertencia que barbante.

Pertencimento é uma questão que surge desse procedimento: é possível identificar na dança do(a) outro(a) a minha vida? Interpretação também é algo a ser refletido: como duas pessoas interpretam o mesmo barbante? Significações igualmente podem ser discutidas: um fio apertado é um momento-charneira difícil? O que um nó frouxo significa? Um nó grande se transforma em um gesto espacialmente grande?

Nos dois procedimentos descritos, a produção de movimentos dançados se constitui, então, uma narrativa, um texto, e problemáticas podem surgir a partir do modo como o(a) estudante irá lidar com o trabalho com a vida real, com as palavras-chave ou momentoscharneira. A questão da autorrepresentação é um cuidado a se perceber. É comum, sobretudo em pessoas que não costumam dançar, criar gestos descritivos que servem para contar a história daquele sentimento, palavra, momento. Temos, então, duas problemáticas: da ordem artística e da ordem formativa. Do ponto de vista artístico, a ideia é a de que o(a) aluno saia da mímese, da reprodução do fato, que transforme em gestos e ações o vivido, mas não de forma figurada. Do contrário, não ampliaremos seus repertórios de movimento, muito menos seus entendimentos a respeito do que seja dança. A arte pode ser abstrata, e simbolizar não significa representar fielmente.

Do ponto de vista formativo - como o campo da Educação tem pensado a Autobiografia -, entendendo a frase coreográfica criada como uma narrativa, recorremos a Chiené (2010, p. 133), que nos alerta que:

Mesmo que o autor vise à autorrepresentação, o texto encontra-se distanciado das suas vivências: engloba-o e ultrapassa-o, estrutura-o à sua maneira. [...] Então, na relação interpretativa do texto, a interpretação do autor pode ser revelada pela intenção do texto. É assim que o texto pode servir de charneira entre a irracionalidade do 'vivido' e a racionalidade do sentido da experiência (grifo nosso).

Em outras palavras, o movimento dançado proposto pode servir como elemento desencadeador de reflexão sobre o vivido. Ao mesmo tempo em que, do ponto de vista estético, pode-se pensar nas escolhas compositivas para a produção daqueles movimentos dançados. 


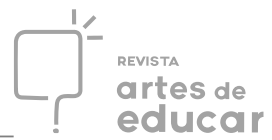

Apesar de não ser o foco a autoformação, no entendimento posto pela pesquisa Autobiográfica, é lógico que, ao se trabalhar com memórias e momentos-charneiras, esta pode vir a ocorrer, uma vez que a reflexão permite a construção (JOSSO, 2010). Aqui, portanto, a escrita de si não ocorre apenas no papel, uma vez que a Autobiografia não se restringe à escrita com caracteres alfabéticos no papel, [...]refere-se às várias formas de escrita de si e a grafia é tudo isso que deixa um traço, um signo (FORTUNA, 2012, p. 182), o que significa que, dançando, nossos(as) estudantes estariam construindo suas formações para além da dança também. Estarão se (re)conhecendo como sujeitos, identificando suas marcas, refletindo sobre como estão se tornando o que são, como estão se autoconstruindo, uma vez que: Traduzir a vida em palavras promete ao narrador obter, contra o risco de se expor, o benefício de clarificar suas atitudes e decisões e, sobretudo, o mérito de aprender a compor versões suficientemente boas de si para melhor agir no mundo (PASSEGI; ABRAHÃO; DELORY-MOMBERGER, 2010, p. 40-41). E caberá ao professor ou professora escolher como trabalhar com essas questões, para além dos conteúdos específicos de dança. Aqui, a dança, serviria, então, como a narrativa de si da Autobiografia como processo autoformativo.

\section{As colonialidades nos sistemas das Artes}

Os estudos decoloniais surgiram na década de 1990, com grupos de intelectuais latinoamericanos, tendo como principal questão decolonizar o conhecimento até então majoritário e centrado na Europa e em autores europeus. Nesse sentido, as perspectivas decoloniais [...] buscam a emancipação de todos os tipos de dominação e opressão, em um diálogo interdisciplinar entre a economia, a política e a cultura (ROSEVICS, 2014, p. 189). O conceito de colonialidade de poder, apresentado e defendido por Aníbal Quijano (2000), fortalece tal abordagem e exprime a importância dos estudos decoloniais para descentralizar narrativas, contextos e modelos eurocentrados no Sistema Mundo (ROSEVICS, 2014). É nessa relação de repensar o mundo e o conhecimento que chegamos ao contexto histórico no qual a Arte também foi afetada por tais colonialidades epistemológicas.

Achinte (2017) destaca que o projeto moderno ocidental foi construído por uma Europa chamada de moderna e inventada ideologicamente, na qual as culturas grega e romana foram tomadas como centros da história mundial, chegando-se ao que conhecemos atualmente por eurocentrismo. Assim, o contexto histórico do projeto de modernidade e o desenvolvimento da Arte foram pautados pela representação, principalmente, por duas 


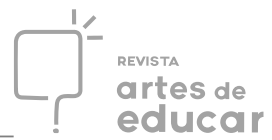

ênfases: a primeira, da Arte como algo belo e imitativo da natureza; a segundo, da ideia de genialidade na criação de obras de Arte.

Segundo Achinte (2017), isso gerou uma compreensão da Arte severamente ligada à beleza, à estética e a um tipo específico de perfeição - permeada por uma colonialidade do poder sobre o conhecimento. Por outro lado, destaca (idem) a importância de uma visão crítica acerca da história para reconhecermos atualmente o contexto que estamos insertos e os processos de investigação que permitam confrontá-los. Desse modo, ao serem incorporadas outras culturas, estéticas, tecnologias alargam-se os horizontes de criação, produção e fruição nas Artes, principalmente, para construir um sentido de arte capaz de gerar um pensamento crítico frente a nossas realidades contemporâneas, mas igualmente frente a nossos passados possíveis de ser re-visitados e ressignificados (ibidem, p. 84)

5 . Isso permite a leitura crítica das produções de Arte, bem como do ato criador do(a) artista e dos(as) alunos(as) na educação básica.

Nesse sentido, a função da Arte, para esse autor (ibidem), é propor uma educação com Arte, na qual perpassa conhecer a história criticamente, ampliando as concepções de Arte, autoafirmando as subjetividades, contextualizando-as, e, sobretudo, questionando a colonialidade do saber, ou seja, porque algo é reconhecido como Arte ou não é. Nas palavras de Achinte (2017, p. 85):

[...] o sujeito se confronta consigo mesmo e com seu entorno, exercendo autonomia imerso em um contexto específico que o afeta, enfrenta suas dúvidas, explora suas sensações, determina seus limites e suas possibilidades e decide como capturar criativamente através de formas e cores na pintura, movimentos na prosa ou na poesia ou imagens que constroem a realidade virtual. ${ }^{6}$

A discussão interpelada por esse autor (idem) diz respeito também ao ensino e aprendizagem da Arte nos sistemas educativos, no qual recai nosso ambiente de aplicação dos procedimentos criados. De acordo com esse pesquisador (ibidem), historicamente, temos visualizado o ensino de Arte baseado em uma associação mecânica entre Arte e Estética, entre ensinar técnicas específicas para criar e alcançar a universalidade da aprendizagem fundamentada em referências eurocêntricas, legitimando colonialidades tanto de saberes, como de poderes sobre os corpos. Assim, destaca (ibidem) que isso é resultado de uma educação pela Arte que, historicamente, seguiu uma tradição educativa, na qual o 


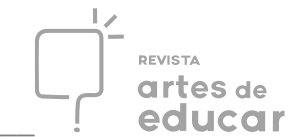

eurocentrismo tomou-se como eixo central. Em contraponto, o teórico propõe a educação com Arte [...] que a arte acompanhe os processos cognitivos, sensoriais e experienciais dos e das estudantes (ibidem, p. 87). ${ }^{7}$

\section{Fragmentos de um corpo decolonial}

Imagem 1: Fragmentos de um corpo decolonial.

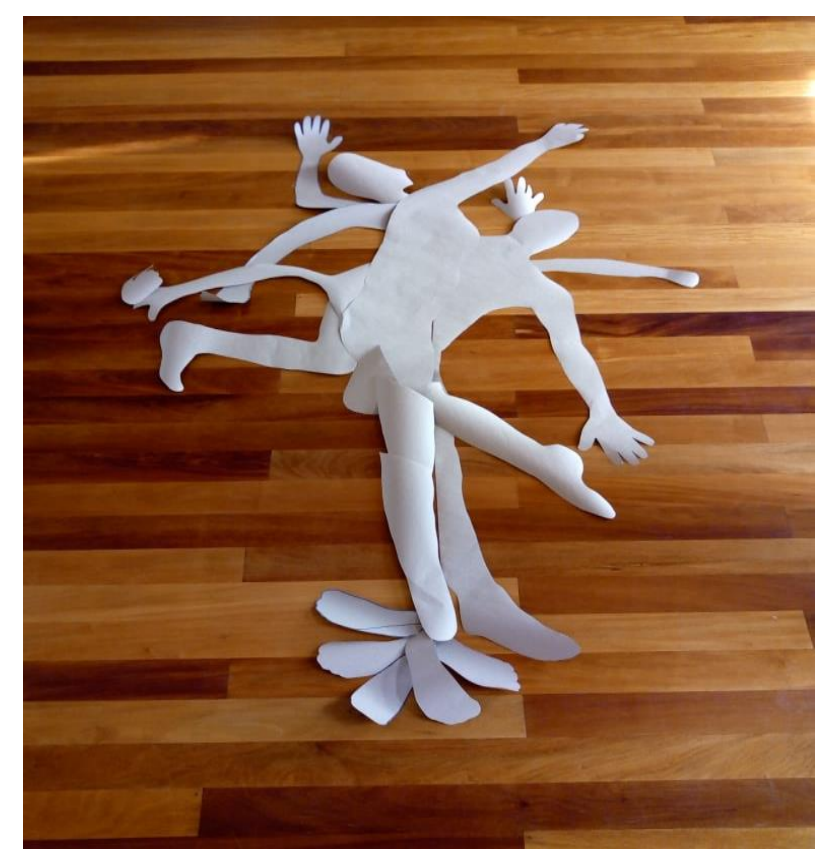

Fonte: Acervo do Grupo Corpografias (2019). Foto: Dos(as) autores(as).

O procedimento criativo em dança, chamado Fragmentos de um Corpo Decolonial, surgiu com os estudos realizados no Grupo Corpografias e teve como ênfase práticas criativas e situadas, apoiadas no conceito de corpo singular, ou ainda, do corpo geopoliticamente localizado e reconhecido por suas genealogias e histórias de vida (ACHINTE, 2017; QUIJANO, 2000). Logo, tal procedimento propôs como principal ação desenhar em um grande papel partes do corpo ou fragmentos da percepção de como reconhecemos o eu-corpo, de cada pessoa (conforme Imagem 1). Posteriormente, recortou-se tais peças, que em um grande número tornam-se formas corporais. Após a elaboração dos desenhos, objetivamos dançar com tais imagens ou, então, criar imagens entre o encaixe de várias partes entre eles. 


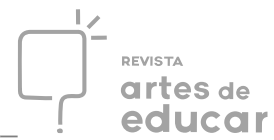

Em outro momento, sugerimos a experimentação de tais imagens ou formas corporais com a pausa e o movimento para, crescentemente, isso tornar-se uma imagem mais fluída e dançada.

Alguns desdobramentos deste procedimento podem ser evidenciados na nossa investigação: um deles propõe que as peças ou as formas corporais sejam distribuídas pela sala de ensaio, a fim de criar um caminho, em que o(a) bailarino(a) ou aluno(as) possa experimentar possibilidades de movimentos conforme se desloca até eles ou, ainda, como as formas corporais se traduzem em movimentos dançados ou pausados. Outro desdobramento possibilita que as peças sejam distribuídas nas paredes da sala de ensaio/aula para que, assim, formem novas ferramentas de investigação e invenção das formas corporais. Para tanto, as formas corporais podem ser utilizadas na construção de um corpo como unidade ou do corpo como coletivo, em que várias partes constituem um eu-corpo por várias mãos, pensamentos, ideias e desejos. O procedimento Corpo Decolonial mostra-nos inúmeras potencialidades para o trabalho artístico e pedagógico, além de fornecer diálogos reflexivos acerca do corpo como autobiográfico e decolonial. Alguns tensionamentos surgiram: como (re)conhecer-se como corpo situado e singular? Essa imagem-corpo (ver imagem 1) criada corresponde à realidade apresentada na sala de aula? Como a criação desse corpo decolonial auxilia na reflexão sobre si e sobre o outro?

Os primeiros resultados das investigações demonstram que o procedimento sempre se reinventa a cada nova retomada, uma vez que as imagens criadas são sempre diferentes das anteriores. Por outro lado, o trabalho com as formas corporais constitui-se como um ato criativo pedagogicamente crítico e que coloca o sujeito como agente de suas escolhas, instigando-o a interpelar a criação, em relação aos demais colegas, bem como incluir outras narrativas do corpo para além do comando de um(a) professor(a). Nesse processo, são atravessadas as ideias de diferença e de reconhecimento do corpo como particular, localizado e histórico, já que os desenhos não só correspondem às formas corporais, mas também a imagens que, muitas vezes, não reconhecemos do corpo. O procedimento elabora de maneira gradativa e, por meio de fragmentos, a multiplicidade de corpos e modos de ver-se e mover-se nos recortes e dobras dos papéis. É um trabalho meticuloso, mas que colabora para o ato criador e da prática artística situada no contexto imagético dos corpos em movimentos ou em pausa. Isso confronta a discussão apresentada acerca da colonialidade do saber, do poder e do ser, já que o conhecimento que está sendo produzido nessa atividade se contrapõe ao pensamento hegemônico de uma aula de Arte. 


\section{Corpomente: Educação Somática}

A Educação Somática surgiu no século XX por profissionais das áreas de saúde, da arte e da educação, em pesquisas empíricas que, posteriormente, passaram a ser investigadas nas universidades. A maioria dos métodos e técnicas criados foram desenvolvidos nos Estados Unidos e na Europa, por criadores que tinham o desejo de curar-se e, para isso, passaram a investigar movimentos em seus corpos. Por isso, colocaram em questão a medicina normalmente praticada no Ocidente. Assim, a partir de suas próprias experiências, os métodos e técnicas foram sistematizados, transmitidos por seus discípulos e discípulas nas décadas seguintes.

Apenas em 1970, o campo foi assim denominado por Thomas Hanna. Após a realização do primeiro simpósio bianual Science and Somatics for Dance, em 1989 e, mais recentemente, com a criação do International Somatic Movement Education and Therapy Association (Ismeta), nos Estados Unidos, e do Regroupement pour L'education Somatique (RES), em Quebec, é que o termo se consolidou.

Importante ressaltar que as técnicas e métodos de Educação Somática percorreram uma trajetória similar - da prática à teorização e que apresentam como pensamento fundador a unificação corpo/espírito do indivíduo (STRAZZACAPPA, 2009a).

Assim, vale trazer o pensar de Strazzacappa (2009a, p. 311), que afirma:

Diferentemente dos coreógrafos, os reformadores de movimento não pensavam na padronização de corpos, nem tinham uma pré-concepção estética. O desenvolvimento de suas técnicas, embora tenham surgido da necessidade de solucionar problemas específicos e mesmo pessoais, tinha como objetivo exatamente o oposto: resgatar a unidade e identidade do Ser Humano. Estas técnicas partiam do principio de que nenhum Ser Humano é igual ao outro e de que estas diferenças deveriam ser respeitadas e mantidas.

Com as premissas acima e os estudos de Miller (2011) e Terra (2011), o grupo de pesquisa desenvolveu três procedimentos específicos de ensino de dança, tendo como pressupostos conceitos da Educação Somática.

O procedimento Formas Diferentes de Dançar foi desenvolvido embasado no pensamento de que [...] tratar o corpo em movimento de forma aberta e abrangente converge com o momento de crescente reflexão a respeito do corpo e de suas fronteiras borradas Revista Interinstitucional Artes de Educar. Rio de Janeiro, V. 6, N.1-pág. 184-203 janeiro-abril de 2020: “Educação: Corpo em movimento II." - DOI: 10.12957/riae.2020.45288 


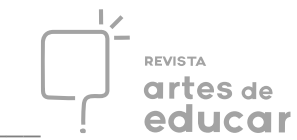

(MILLER, 2011, p. 152). Ao imaginarmos as formas abertas e as fronteiras borradas, criamos um procedimento no qual um elástico se transforma na moldura do quadro do movimento. Em outras palavras, cada participante tem um elástico de cerca de três metros com o qual ele investigava movimentos, dentro e fora dos espaços criados pelos elásticos ou amarrado em partes do seu corpo, pensando em voltar-se para si, utilizando um elemento, para, consequentemente, voltar-se a percepção do eu e o outro no mesmo espaço - quando dois participantes trabalhariam juntos -, criando diversos caminhos e atravessamentos com os elásticos, relacionando com o entrar na forma do outro, criando outra, e saindo da forma. Isso porque, na Educação somática. Como salienta Miller (2011, p. 153):

[...] o indivíduo em trabalho técnico está em ação investigativa de sua relação com o próprio corpo, com o corpo do outro, com o ambiente/espaço e com a sua percepção aguçada no momento presente para a criação de outro momento/movimento. Por isso, podemos falar de um corpo em relação, ou seja, uma atenção do corpo em relação ao todo, ao outro, ao espaço, ao ambiente, numa rede de percepções.

Nesse procedimento, pode-se ir além da investigação da relação do próprio corpo com o corpo do outro. Uma variação proposta é a de investigar a relação com o ambiente/espaço, com a colocação do elástico num ponto fixo, trabalhado a tensão espacial, pesquisando movimentos entre os elásticos e o ponto fixo, dialogando com o espaço do outro. Os conteúdos desse procedimento foram: formas, tensão espacial e 'kinesfera', para adolescentes.

Ao realizar o procedimento com o grupo, podemos constatar alguns questionamentos, tais como: as diferentes formas de envolver-se no elástico produzem formas corporais abstratas, deformadas, não usuais, o que nos instiga a pensar em corpos diversos na dança que corpos podem dançar? Como esses diferentes corpos, singulares, nas suas especificidades, se movem? Estas indagações nos levam a pensar na inclusão de pessoas com deficiência na dança. Outra questão que surge está relacionada às maneiras de conduzir o outro e ser conduzido. Por exemplo, com o elástico posso conduzir uma pessoa sem necessariamente tocar nela. No caso específico das pessoas com deficiência, o procedimento nos permite investigar formas de deslocamentos com elas. Por outro lado, a condução do(a) colega, com o elástico, nos defronta também com uma questão da ordem ética: em que medida a condução não é manipulação ou em que medida o(a) outro não é uma marionete? 


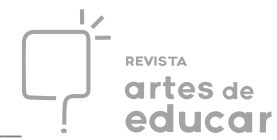

Outros dois procedimentos criados pelo grupo se referenciavam aos sentidos: paladar e tato. O primeiro, PalaDança, propõe que os (as) estudantes provem sabores diversificados, de olhos fechados, e façam uma escrita sobre a sensação do que aqueles sabores causam. Posteriormente, esta escrita é revisitada e movimentos são criados para ela. O outro procedimento, Texturas para a Dança, são escolhidas parte do corpo (mão ou pé) que entrarão em contato com diferentes texturas de tecidos. De olhos fechados, dançam-se as sensações que reverberam na pessoa com os diferentes toques.

Relações de aproximação entre as sensações e ações do corpo trazem a comunicação entre razão e sensibilidade. Os procedimentos iniciam-se nos sentidos - nesse caso, paladar e tato -, indo para a área de lembranças e do afetivo e, em seguida partindo desses elementos para criar movimento. É um ato não só racional como sensível. A linha de onde começa um e termina outro é extremamente estreita, demonstrando como é importante não hierarquizar.

Tiburi (2005 apud TERRA, 2011, p. 167) afirma que:

O que melhor resume a sensibilidade é que ela é uma capacidade de ter atenção às coisas, o modo como nos dispomos ao que não somos e não sabemos. O uso da razão, a produção do pensamento, depende desse gesto inicial de disposição, que envolve silêncio, a boa passividade e a escuta.

$\mathrm{Na}$ atualidade, esses procedimentos se tornam ainda mais relevantes, pois vivemos em espaços e tempos maquínicos, nos quais há empobrecimento dos sentidos, devido ao excesso de estímulos, que não temos o tempo devido para processar de forma adequada cada uma das informações. Terra (2011, p. 171) corrobora esse assunto quando nos alerta sobre se tornar sensível: "Sensibilizar-se significa tornar-se sensível a algum estímulo, tornar-se receptivo, deixar-se afetar por informações que chegam ao entorno ou do próprio corpo”, e levanta também a ideia de Laban, do "saber-sentir".

Cabe lembrar que Suquet (2008, p. 525 apud TERRA, 2011, p. 168) afirma:

[...] Do elevador às montanhas russas, passando pelo filme ou fotografia, as tecnologias da Era Industrial suscitam experiências perceptivas inéditas. Rupturas espácio-temporais, solavancos, acelerações induzem coordenações cinestésicas e novas modalidades de comportamento. Aos olhos de Laban, esse regime do instantâneo, próprio da vida moderna, comporta, no entanto, um perigo: oblitera a memória, não deixa que a experiência se sedimente. Daí um empobrecimento da vida sensorial e emocional, uma capacidade de relação ao mundo cada vez mais lacunosa. 


\section{Singularidade do ser}

A singularidade do ser talvez seja a grande convergência dos três campos epistemológicos aqui apresentados. Isso porque, por exemplo, os reformadores do movimento - pioneiros que criaram os primeiros métodos e técnicas somáticas - partiam da premissa de [...] que nenhum ser humano é igual ao outro e de que estas diferenças deveriam ser respeitadas e mantidas. (STRAZZACAPPA, 2009b, p. 49). Por sua vez, o pensamento decolonial - e suas pedagogias - propõem, segundo Espinoza et al. $(2013 \text {, p. } 417)^{8}$ :

[...] uma forma de conhecer e fazer encarnada em corpos individuais e coletivos, encarnada nas experiências subjetivas, corpóreas e emocionais [...], integram o que a modernidade dicotomizou e hierarquizou: corpo e mente, emoção e razão, individualidade e coletividade se articulam para a partir dali aprender e não só modificar os discursos e prática que fazem e desfazem os corpos.

Temos evidente, na Autobiografia, a singularidade da pessoa, pois o exercício de desvelamento que caracteriza a pesquisa autobiográfica fundamenta-se na memória. A memória assinala a nossa singularidade, direcionando as possibilidades de ser e fazer (CUNHA, 2012, p. 101).

Explícito aqui também outra relação, que tem coligação com a singularidade do ser: a não separação 'corpomente' - compreendida desse modo tanto na Educação Somática quanto na decolonialidade. Em dança, isso significa um pensamento outro sobre o corpo: que deixa de ser instrumento e passa a ser sujeito. Importante ressaltar que esse entendimento 'corpomente' possibilita que não exista hierarquia em relação aos conhecimentos diversos: não existe primazia da razão, mas também a emoção é considerada, como afirmam Mignolo e Vásques (2017, p. 496) a respeito da pedagogia decolonial.

Com Espinosa et al. (2013), é preciso lembrar também que esse ser singular tem o conhecimento corporalizado que, como podemos perceber, não é apenas referente à decolonialidade. Na autobiografia, por exemplo, Josso (2004, p. 126) indica o movimento como forma de acesso às memórias e, porque não pensar também, ao conhecimento, quando afirma que o relaxamento, por exemplo, [...] é uma condição não apenas para poder estar disponível em seguida, mas também para facilitar a rememoração. Por sua vez, na educação somática, de acordo com Fortin (2004), o campo valoriza o corpo vivido e permite uma 


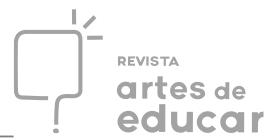

autoformação criadora, que acaba por fazer com que o(a) aluno(a) se (re)aproprie de seu corpo, que perceba que ele é fonte de saber e, nessa medida, deixe de ser vulnerável ao poder de outro sobre si. Ademais, não se pode esquecer que esse conhecimento corporalizado é também situado, localizado geopoliticamente. E, nessa perspectiva, portanto, pode-se considerar que estas experiências anteriores dizem respeito também às ancestralidades e a modos de ser e estar no mundo de cada um nos seus lugares de origem.

Como em uma espiral, na qual um tema leva a outro, segundo Oliveira e Candau (2010, p. 23), o conhecimento situado nos permite refletir sobre as marcas:

Outro conceito central, introduzido por Mignolo, é a diferença colonial, entendida como pensar a partir das ruínas, das experiências e das margens criadas pela colonialidade do poder na estruturação do mundo moderno/colonial, como forma não de restituir conhecimento, mas de reconhecer conhecimentos "outros" em um horizonte epistemológico transmoderno, ou seja, construído a partir de formas de ser, pensar e conhecer diferentes da modernidade europeia, porém em diálogo com esta.

Se do ponto de vista da decolonialidade nossas marcas são a ferida colonial e que, como nos lembra Marín (2013), se encontram nos sujeitos e seus corpos, do ponto de vista da autobiografia essas marcas outras - como os momentos-charneiras - nos constituem e, para a Educação Somática, são marcas corpografadas (BALDI, 2014), ou seja, inscritas e escritas no nosso movimento.

Uma proposta pedagógica a partir dos pressupostos da Autobiografia, da Decolonialidade e Educação Somática irá considerar que cada ser é único e tem suas peculiaridades, o que significa acolher suas experiências anteriores no ato educativo.

\section{Conclusões}

O desenvolvimento de procedimentos de ensino e criação em dança, com os três campos epistemológicos, nos permite perceber que o pessoal e o coletivo estão imbricados, ou seja, mesmo quando nos referimos a questões eminentemente pessoais, às vezes, até de foro íntimo, estas são também universais.

As vivências em dança com essas perspectivas promovem discussões a respeito de pertencimento, interpretação e significação. Permitem, ainda, um ensino crítico, reflexivo e, 


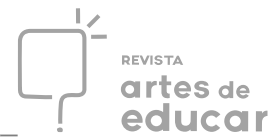

por isso, autoformativo - no sentido empregado pela Autobiografia no campo da Educação. Podemos inferir, ainda, que concepções pedagógicas advindas desses campos epistemológicos, tendo em vista nossa experiência vivida, promovem a autonomia do sujeito, que se coloca como agente de suas escolhas e o instiga a se autointerpelar. O que significa, portanto, que promovem atos educativos, cuja criticidade é um componente importante.

Nossas escolhas metodológicas foram importantes também para discussões a respeito da democracia dos corpos: porque temos outro entendimento acerca do corpo, compreendemos que todos os corpos podem dançar. Do mesmo modo que instigam questionamentos sobre o que rememoramos ou esquecemos, do que damos a ver e/ou escondemos, de como nos constituímos como sujeitos - unos e coletivos. O que nos permitimos socialmente? Que máscaras carregamos? Quando dançamos, conseguimos ser quem somos ou necessitamos nos esconder? As aprendizagens, com dança, em uma perspectiva autobiográfica, decolonial e somática, permitem que reconheçamos quem somos, quem estamos sendo e se, no ato educativo, estamos nos aprisionando ou se podemos ser quem somos. Em uma atualidade cada vez mais doente e preconceituosa, permitir-se ser quem se é, reconhecer como um sujeito singular, situado geopoliticamente, pode significar a aceitação não apenas de si, mas do outro, do diferente. Nesse sentido, a dança pode ser uma importante porta para esses acessos e essas interpelações.

Compreendemos, ainda, que as perspectivas aqui apresentadas confrontam as colonialidade constituídas, bem como o pensamento hegemônico de uma aula de Arte e, até porque não, o pensamento instituído na escola de forma geral: que prioriza a razão à emoção, que hierarquiza conhecimentos. Segundo Silva e Santiago (2016, p. 79), o pensamento decolonial deseja fundar um pensamento 'outro' (WALSH, 2008) que afirme a necessidade de mudar não só as relações, mas também as estruturas, condições e dispositivos de poder [...]. Por meio da dança, na perspectiva autobiográfica, decolonial e somática, acreditamos que podemos fazer transformações, não apenas no modo como ensinamos e aprendemos essa linguagem artística, mas também no campo da educação.

\section{REFERENCIAS}

ACHINTE, Adolfo Albán. Prácticas creativas de re-existencia basadas en lugar: más allá del arte... el mundo de lo sensible. Ciudade Autónoma de Bueno Aires: Del Signo, 2017. 


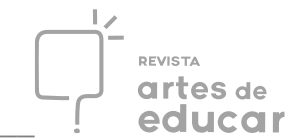

BALDI, Neila. (Ins)(Es)critas no/do corpo dançante. In: CONGRESSO CONFAEB. Anais..., XXIV, Londrina, 2014.

CHIENÉ, Adéle. A narrativa de formação e a formação de formadores. In: NÓVOA, António. FINGER, Matheus. O método (auto)biográfico e a formação. São Paulo: Paulus. Natal: Editora da UFRN, 2010. p. 129-141.

CUNHA, Jorge Luiz da. Pesquisas com (auto)biografias: interfaces em tempos de individuação. In: PASSEGGI, Maria da Conceição; ABRAHÃO, Maria Helena Menna Barreto. (orgs.). Dimensões epistemológicas e metodológicas da pesquisa (auto)biográfica. Tomo I. Natal: EDUFRN; Porto Alegre: EDIPUCRS; Salvador: EDUNEB, 2012. p. 95-114.

DELORY-MOMBERGER, Christine. A pesquisa biográfica: projeto epistemológico e perspectivas metodológicas. In: PASSEGI, Maria da Conceição; ABRAHÃO, Maria Helena Menna Barreto. (Orgs.). Dimensões epistemológicas e metodológicas da pesquisa (auto)biográfica. Tomo I. Natal: EDUFRN; Porto Alegre: EDIPUCRS; Salvador: EDUNEB, 2012. p. 71-94.

ESPINOSA, Yuderkys; GÓMEZ, Diana; LUGONES, María; OCHOA, Karina. Reflexiones pedagógicas en torno al feminismo descolonial. In: WALSH, Catherine. Pedagogías decoloniales: práticas insurgentes de resistir, (re)existir y (re)vivier. Tomo I. Quito: Ediciones Abya-Yala, 2013. p.403-442.

FORTIN, Sylvie. Transformação de práticas de dança. In: PEREIRA, Roberto e SOTER, Silvia. Lições de dança 4. Rio de Janeiro: UniverCidade, 2004.

FORTUNA, Tânia Ramos. Ludobiografia: uma invenção metodológica em pesquisa (auto)biográfica em educação. In: PASSEGI, Maria da Conceição; ABRAHÃO, Maria Helena Menna Barreto. (Orgs.). Dimensões epistemológicas e metodológicas da pesquisa (auto)biográfica. Tomo II. Natal: EDUFRN; Porto Alegre: EDIPUCRS; Salvador: EDUNEB, 2012. p. 165-202.

FOUCAULT, Michel. A escrita de si. In: FOUCAULT, Michel. O que é um autor? Lisboa: Passagens. 1992. p. 129-160.

GREBLER, Betti. Pina Bausch e Maguy Marin: teatralidade e corporeidade contemporânea. In: XAVIER, Jussara; MEYER, Sandra; TORRES, Vera. Coleção Dança Cênica: Pesquisas em dança, vol. 1. Joinville: Letradágua, 2008.p. 101-107.

JOSSO, Marie-Christine. Da formação do sujeito...Ao sujeito da formação. In: NÓVOA, António. FINGER, Matheus. O método (auto)biográfico e a formação. São Paulo: Paulus. Natal: Editora da UFRN, 2010. p.59-80.

JOSSO, Marie-Christine. Experiências de vida e formação. São Paulo: Cortez, 2004.

MARÍN, Pilar Cuevas. Memoria colectiva: Hacia un proyecto decolonial. In: WALSH, Catherine. Pedagogías decoloniales: prácticas insurgentes de resistir, (re)existir y (re)vivir. Tomo I. Quito: Ediciones Abya-Yala, 2013. 
MIGNOLO, Walter. VÁSQUEZ, Rolando. Pedagogía y (de)colonialidad.In: WALSH, Catherine. Pedagogías decoloniales: práticas insurgentes de resistir, (re)existir y (re)vivier. Tomo II. Quito: Ediciones Abya-Yala, 2017. p.489-508.

MILLER, Jussara. Dança e educação somática: a técnica na cena contemporânea. In: WOSNIAK, Cristiane. MARINHO, Nirvana (Org.) Seminários de Dança: O avesso do avesso do corpo, educação somática como práxis. Joinville: Nova Letra, 2011. 147-161

OLIVEIRA, Luiz Fernandes de Oliveira. CANDAU, Vera Maria Ferrão Candau Pedagogia decolonial e educação antirracista e intercultural no Brasil. Educação em Revista, Belo Horizonte, v.26, n.01, abr. 2010, p.15-40.

OLIVEIRA, Valeska Fortes. A escrita como dispositivo na formação de professores. In: : PERES, Lúcia Maria Vaz; ZANELLA, Andrissa Kemel (org). Escritas de autobiografias educativas: o que dizemos e o que elas nos dizem? Curitiba: CRV, 2011.

PASSEGGI, Maria da Conceição; ABRAHÃO, Maria Helena Menna Barreto; DELORYMOMBERGER, Christine. Reabrir o passado, inventar o devir: a inenarrável condição biográfica do ser. In: PASSEGI, Maria da Conceição. ABRAHÃO, Maria Helena Menna Barreto. (org.). Dimensões epistemológicas e metodológicas da pesquisa (auto)biográfica: Tomo II. Natal: EDUFRN; Porto Alegre: EDIPUCRS; Salvador: EDUNEB, 2012. p. 29-58.

PERES, Bruna Bellinazzi. Desvelando memórias: afetos e autobiografia cênica. Rascunhos, Uberlândia, v. 1 n. 1 p. 76-88, jan.jun. 2014.

QUIJANO, Aníbal. Colonialidad del poder, eurocentrismo y América Latina. In: LANDER, Edgardo (org). La colonialidade del saber: eurocentrismo y ciencias sociales, perspectivas latinoamericanas. Buenos Aires: CLACSO, 2000. p. 193-238.

RIBEIRO, António Pinto. Por exemplo a cadeira: ensaio sobre as artes do corpo. Lisboa: Cotovia, 1997.

ROSEVICS, Larissa. Do pós-colonial à decolonialidade. In: CARVALHO, Glauber.

(Org.). Diálogos Internacionais: reflexões críticas do mundo contemporâneo. Rio de Janeiro: Perse, 2017.

SILVA, Claudilene. SANTIAGO, Eliete. Pensamento negro e educação intercultural no Brasil. Interterritórios - Revista de Educação, Recife, v.2, n.3, p. 78-100, p. 2016.

STRAZZACAPPA - As técnicas de educação somática In: BOLSANELLO, Débora Pereira (org). Em pleno corpo - educação somática, movimento e saúde. Curitiba: Juruá Psicologia, 2009a.

STRAZZACAPPA, Márcia. Educação somática: princípios e possíveis desdobramentos. Repertório - Teatro e Dança, Salvador, ano 12, número 13, p. 48-54, 2009.2.

TERRA, Ana. Saberes sensíveis no trânsito somático-dançante. In: WOSNIAK, Cristiane. MARINHO, Nirvana (Org.) Seminários de Dança: $O$ avesso do avesso do corpo, educação somática como práxis. Joinville: Nova Letra, 2011. p. 163-183. 


\title{
VIEIRA, Marcílio de Souza. História das ideias do ensino da dança na educação brasileira. Curitiba: Appris, 2019.
}

\author{
WALSH, Catherine. Interculturalidad, plurinacionalidad y decolonialidad: las \\ insurgencias político-epistémicas de refundar el Estado. Tabula Rasa. Bogotá - Colombia,
} No.9: 131-152, julio-diciembre 2008.

\section{WOODRUFF, Diane. Treinamento na dança: visões mecanicistas e holísticas. Cadernos do GIPE-CIT, Salvador, n. 2, p. 17-30, fev. 1999.}

\begin{abstract}
${ }^{\text {i }}$ Professora Assistente do Curso de Dança-Licenciatura. Doutora em Artes Cênicas pela UFBA. Coordenadora do Grupo de Pesquisa sobre (Es)(Ins)critas do/no Corpo. E-mail: neila.baldi@ufsm.br. Santa Maria, Rio Grande do Sul - Brasil. ORCID: https://orcid.org/0000-0002-4431-4998.

ii Artista da Dança. Licenciado em Dança pela Universidade Federal de Santa Maria. Bolsista do Fundo de Incentivo à Pesquisa (Fipe) do Grupo de Pesquisa sobre (Es)(Ins)critas do/no Corpo. E-mail: fio.sb.14@hotmail.com. Santa Maria, Rio Grande do Sul - Brasil. ORCID: https://orcid.org/0000-0003-0319-
\end{abstract} 3269.

iii Artista da Dança. Licenciada em Dança pela Universidade Federal de Santa Maria. Bolsista voluntária do Grupo de Pesquisa sobre (Es)(Ins)critas do/no Corpo. E-mail: fabianna.mors@ @otmail.com. Santa Maria, Rio Grande do Sul - Brasil. ORCID: https://orcid.org/0000-0002-5709-9377.

iv Artista da Dança. Graduanda em Dança Licenciatura pela Universidade Federal de Santa Maria. Bolsista do Programa Institucional de Bolsas de Iniciação Científica (PIBIC) Grupo de Pesquisa sobre (Es)(Ins)critas do/no Corpo. E-mail: cineujahr@gmail.com. Santa Maria, Rio Grande do Sul - Brasil. ORCID: https://orcid.org/00000003-1305-6719.

5 “[...] construir un sentido del arte capaz de generar un pensamiento crítico frente a nuestras realidades contemporáneas, pero igualmente frente a nuestros pasados posibles de ser re-visitados y resignificados" (ACHINTE, 2017, p. 84,).

${ }^{6}$ En el que el sujeto se confronta consigo mismo y con su entorno, haciendo autonomia inmerso en un contexto específico que lo afecta, se enfrenta a sus dudas, explora sus sensaciones, determina sus límites y sus posibilidades y decide cómo plasmar creativamente a través de formas y colores en pintura, movimientos en la prosa o en la poesía o imágenes que se construyen en la realidad virtual. (ACHINTE, 2017, P. 85).

7 "que el arte acompañe los procesos cognitivos, sensoriales y experienciales de los e las estudiantes" (ACHINTE, 2017, p. 87).

${ }^{8}$ Esta pedagogía es una forma de conocer y hacer encarnada en los cuerpos individuales y colectivos, encarnada desde las experiencias subjetivas, corpóreas y emocionales de las mujeres que luchan. De esa manera integran lo que la modernidad a dicotomizado y jerarquizado: cuerpo y mente, emoción y razón, individualidad y colectividad se articulan para desde allí aprender y no sólo modificar los discursos sino las prácticas que hacen y deshacen los cuerpos." (ESPINOSA et al., 2013, 417) 